\title{
Use and preferences regarding internet-based health care delivery in patients with chronic kidney disease
}

\author{
Lena Schiffer ${ }^{1,4^{*}} \mathbb{D}$, Raoul Gertges ${ }^{4}$, Mariel Nöhre ${ }^{2,4}$, Elisabeth Schieffer ${ }^{4,5}$, Uwe Tegtbur ${ }^{4,5}$, Lars Pape ${ }^{1,4 \dagger}$,
} Martina de Zwaan ${ }^{2,4+}$ and Mario Schiffer ${ }^{3,4+}$

\begin{abstract}
Background and objectives: Internet-based technologies play an increasingly important role in the management and outcome of patients with chronic kidney disease (CKD). The healthcare system is currently flooded with digital innovations and internet-based technologies as a consequence of the coronavirus disease 2019 (COVID-19) pandemic. However, information about the attitude of German CKD-patients with access to online tools towards the use of remote, internet-based interactions such as video conferencing, email, electronic medical records and apps in general and for health issues in particular, are missing.
\end{abstract}

Design, setting, participants, and measurements: To address the use, habits and willingness of CKD patients in handling internet-based technologies we conducted a nationwide cross-sectional questionnaire survey in adults with CKD.

Results: We used 380 questionnaires from adult CKD patients (47.6\% on dialysis, $43.7 \%$ transplanted and 8.7\% CKD before renal replacement therapy) for analysis. Of these $18.9 \%$ denied using the internet at all (nonusers). Nonusers were significantly older (74.4 years, SD 11.4) than users (54.5 years, SD 14.5, $\mathrm{p}<0.001$ ), had a lower educational level than users ( $\geq 12$ years: $6.9 \%$ versus $47.1 \%, p<0.001)$ and were more often on dialysis. Within the group of internet users only a minority (2.6\%) was using video conferencing with their physician, only $11.7 \%$ stated that they were using email to report symptoms and $26.6 \%$ were using the internet to schedule appointments. Slightly more than one-third of internet users (35.1\%) are concerned that their personal medical data are not safe when submitted via the internet.

Conclusions: Within our group of German CKD-patients we found that almost one out of five patients, especially older patients and patients with a lower educational level, did not use the internet at all. The majority of internet users reported in our survey that they have not used internet-based technologies within a medical context so far, but are willing to consider it. Therefore, it seems to be important to introduce and teach motivated CKD-patients the use and benefits of simple and safe internet-based health care technologies.

Keywords: Chronic kidney disease (CKD), Video conferencing, eHealth, Internet-based technologies, Coronavirus disease 2019 (COVID-19)

*Correspondence: schiffer.lena@mh-hannover.de

†Lars Pape, Martina de Zwaan and Mario Schiffer contributed equally to this work

${ }^{1}$ Department of Pediatric Kidney, Liver and Metabolic Diseases, Hannover Medical School, Carl Neuberg Str. 1, 30625 Hannover, Germany

Full list of author information is available at the end of the article

\section{Background}

The use of internet-based health care delivery tools is expanding worldwide [1]. The coronavirus disease 2019 (COVID-19) pandemic accelerated this development since internet-based health care services can help to minimize in-person care appointments and still maintain 
access to health-care, which is especially important for vulnerable patient groups [2-4]. Internet-based health care delivery is usually defined as the distribution of health-related services and information via internet technology and comprises in particular health care apps, electronic patient records and online video consultations. These technologies can improve the patient's health and reduce costs for health care systems [5]. Moreover, it is well accepted that internet-based technologies can enhance patient autonomy and improve clinical outcome in a variety of common chronic diseases, such as chronic kidney disease (CKD), diabetes mellitus and asthma bronchiale $[6,7]$. In addition, patients in medically underserved areas, patients with disabilities, who may have difficulties visiting a clinic, or patients with rare diseases who are dependent on highly specialized centers, benefit from the opportunities of internet-based interactions with their physicians which enables them to bridge distances [8].

In the US the provision of internet-based programs for patients on dialysis changed drastically. Before 2018, the dialysis patient needed to be in an approved originating site during the telehealth encounter, such as certain hospitals, doctor's offices, hospital-based dialysis centers, and skilled nursing facilities. However, the Bipartisan Budget Act of 2018 included the home of a dialysis patient as an additional site of health care delivery for home dialysis patients providing more independence for CKD patients [9]. Important regulatory issues and financial reimbursements for services provided through internet-based technologies were recently also clarified in Germany and open the use for a broader application [10-12]. A variety of clinical trials that investigate and evaluate new remote, internet-based models regarding direct patient to caregiver interactions were recently financially supported by several governmental and nongovernmental grants $[13,14]$. The results of these studies can be expected in the near future. In general, these internet-based technologies for the exchange of knowledge place the patient in an active role and require the ability to use electronic devices. However, little is known about the habits and willingness of patients with chronic kidney disease (CKD) regarding the use of digital devices. CKD is a major public health concern with more than 70 million affected individuals worldwide and often leads to end-stage renal disease that requires renal replacement strategies such as dialysis or renal transplantation [15]. These are major cost drivers for health-care systems in developed countries [16-18]. Particularly for CKDpatients different clinical studies have shown that remote, internet-based management systems may improve the care of patients with advanced CKD, decrease the burden of time patients spend in medical visits and are clinically useful [19-22]. Initially, internet-based interventions were used at organizational levels (e.g. for information exchange between hospitals and doctors office) or to monitor dialysis, especially home dialysis outcomes. However, direct patient involvement in eHealth systems and patient-reported outcome measures based on internet technologies are increasing and are expected to improve outcomes and patient satisfaction [23].

Patients with CKD and end-stage renal disease are especially dependent on regular medical consultations due to their fragile and complex medical conditions. Close monitoring for disease progression and a coordinated transition to renal replacement therapy is essential. General parameters that are frequently assessed by the patient or his/her general practitioner, e.g. basic laboratory results, weight gain and blood pressure, are needed by the specialists for evaluation and initiation of further therapy. If these data can be transferred to the specialist remotely and without delay, there is, in many cases, no urge for a personal consultation by a nephrologist $[19,21,22]$. It has to be considered that patients with chronic diseases as CKD are often older and of a lower socioeconomic status $[19,24]$. This is of interest since a lower socioeconomic status or older age are factors that contribute to differences in internet-access and lead to the so-called digital divide $[19,25]$. We analyzed in this study for the first time the user status and the motivation of CKD patients to use internet-based technologies in Germany.

\section{Methods}

\section{Recruitment}

Self-report questionnaires were distributed to patients with CKD by their health-care providers, the magazine "the kidney patient" of the German patient association "Bundesverband Niere e.V." and via the website of the innovation project NTx360 (www.ntx360grad.de). The participants in the study were allowed to submit the selfreport questionnaire electronically or by mail. A prepaid envelope was provided. The response rate was 547 submissions. 380 were complete for age, gender, educational level, user status and therapy. Participants for this study had to be 18 years or older. All participants provided their written informed consent in accordance with the Helsinki declaration. The study was approved by the ethics committee of the Medical School of Hannover.

The following sociodemographic data were assessed: Sex (male and female), year of birth, years of school-education, occupational status (full-time, part-time, retired, disability pension, others). The following health-related determinants were assessed: time on dialysis (subdivided into patients $1-5$ years, $>5$ years and $>10$ years on 
dialysis), kidney transplantation, and chronic kidney disease without the need for dialysis.

Participants were initially asked about how often they use the internet in general (never), sporadic (less than 1 day/week), frequently (1-3 days of the week), regularly (on 4-6 days of the week) and daily (every day).

Questions were chosen with the help of physicians of the Hannover Medical School who are involved in internet studies of CKD patients [13, 14] and were modified from the questionnaire study by Paslakis et al., who examined in a nationwide study the use and preferences regarding internet health care delivery in the general German population [26]. The questions were short and target-oriented and can be found in the Additional file 1 .

\section{Statistical analysis}

Statistical analyses were performed using SPSS Statistics for Windows version 25.0 (IBM Corp.). Descriptive statistics (percentages, means and standard deviations) were calculated. Analyses of variance, T-tests and Chi-square tests for comparison between groups (users versus nonusers, males versus females, different treatment groups) and binary logistic regression analysis were conducted as appropriate. The level of significance was set at $\mathrm{p} \leq 0.05$.

\section{Results \\ Cohort}

A total of 380 data sets from individuals with CKD that were complete for age, gender, educational level, user status and therapy were used for analysis in this study. Patients from all federal states of Germany participated (Additional file 2: Figure S1).

The cohort consisted of 156 (41.1\%) females and 224 $(58.9 \%)$ males. Mean age was 64.5 years with a range from 18 to 93 years. Overall 181 (47.6\%) reported to be on dialysis, 166 (43.7\%) to be transplanted and $33(8.7 \%)$ to suffer from CKD. More details on the sociodemographic information of the cohort are shown in Table 1.

\section{Self-identified Internet users versus nonusers}

When comparing internet users and nonusers, no difference in sex distribution was found. However, age, educational level and treatment of end-stage renal disease differed significantly between groups. Nonusers

Table 1 Comparison between male and female participants regarding sociodemographic factors

\begin{tabular}{|c|c|c|c|c|}
\hline & Total & Males & Females & $\begin{array}{l}\text { Statistics } \\
\text { Chi-square }\end{array}$ \\
\hline$N(\%)$ & 380 & $224(58.9 \%)$ & $156(41.1 \%)$ & \\
\hline \multicolumn{5}{|l|}{ Age categories (years) } \\
\hline $18-34$ & $35(9.2 \%)$ & $12(5.4 \%)$ & $23(14.7 \%)$ & $x^{2}=17.547(d f=4), p=.002$ \\
\hline $35-44$ & $38(10 \%)$ & $18(8.0 \%)$ & $20(12.8 \%)$ & \\
\hline $45-54$ & $58(15.3 \%)$ & $30(13.4 \%)$ & $28(17.9 \%)$ & \\
\hline $55-64$ & 125 (32.9\%) & $85(37.9 \%)$ & $40(25.6 \%)$ & \\
\hline $65+$ & $124(32.6 \%$ & $79(35.3 \%)$ & $45(28.8 \%)$ & \\
\hline Educational level & & & & $x^{2}=0.008(d f=1), p=0.93$ \\
\hline$<12$ years & $230(60.5 \%)$ & $136(60.7 \%)$ & $94(60.3 \%)$ & \\
\hline$\geq 12$ years & $150(39.5 \%)$ & $88(39.3 \%)$ & $62(38.7 \%)$ & \\
\hline Current occupation & & & & $x^{2}=18.444(d f=5), p=.002$ \\
\hline Full-time & $91(23.9 \%)$ & $63(28.1 \%)$ & $28(18.2 \%)$ & \\
\hline Part-time & $50(13.2 \%)$ & $20(8.9 \%)$ & $30(19.5 \%)$ & \\
\hline Not working & $13(3.4 \%)$ & $7(3.1 \%)$ & $6(3.9 \%)$ & \\
\hline \multicolumn{5}{|l|}{ Retired } \\
\hline Old-age pension & $125(33.1 \%)$ & $84(37.5 \%)$ & $41(26.6 \%)$ & \\
\hline Early retirement & $76(20.1 \%)$ & $37(16.5 \%)$ & $39(25.3 \%)$ & \\
\hline Others & $25(6.6 \%)$ & $13(5.8 \%)$ & $10(6.5 \%)$ & \\
\hline \multicolumn{5}{|l|}{ Treatment group } \\
\hline Dialysis patients, $1-5$ years & $109(28.7 \%)$ & $67(29.9 \%)$ & $42(26.9 \%)$ & $x^{2}=4.993(d f=4), p=0.29$ \\
\hline Dialysis $>5$ years & $40(10.5 \%)$ & $28(12.5 \%)$ & $12(7.7 \%)$ & \\
\hline Dialysis > 10 years & $32(8.4 \%)$ & $19(8.5 \%)$ & $13(8.3 \%)$ & \\
\hline Transplant patients & $166(43.7 \%)$ & $95(42.4 \%)$ & $71(45.5 \%)$ & \\
\hline $\begin{array}{l}\text { CKD patients (no renal replacement } \\
\text { therapy) }\end{array}$ & $33(8.7 \%)$ & $16(6.7 \%)$ & $18(11.5 \%)$ & \\
\hline
\end{tabular}


were significantly older (74.4 years, SD 11.4) than users (54.5 years, SD $14.5, \mathrm{p}<0.001)$ and had a lower educational level $(<12$ years: $93.1 \%$ versus $52.9 \%, \mathrm{p}<0.001)$. A significant difference was found between nonusers and users regarding the rate of patients being on dialysis, being transplanted, and CKD patients without renal replacement therapy $(\mathrm{p}<0.001)$. Dialysis patients were more often nonusers independent of the time of dialysis treatment ( $1-5$ years, $>5$ years or $>10$ years). In contrast, transplant patients and CKD patients without renal replacement therapy reported more often to be internet users. Only $1(1.4 \%)$ out of the 166 transplanted participants and 1 (1.4\%) out of the 33 participants with CKD self-identified as nonusers. In Table 2 demographics of user groups are depicted, more details about the results concerning the willingness of adult internet users to consider the use of internet technologies within a medical context of consultation or treatment as well as their actual experiences with technologies of this kind within this specific context are shown in Tables 4 and 5 . When we performed binary logistic regression analysis with the user status as the dependent variable, we found that treatment group and educational level remained significant predictors while user status was not entirely explained by age (Table 3 ).

\section{Actual experience and willingness of patients to use internet, email and video conferencing within a medical context}

When we asked the patients if they used the internet in general for work or for private purposes 72 (18.9\%) denied using the internet at all (nonusers), while 308

Table 2 Comparison between user groups

\begin{tabular}{|c|c|c|c|}
\hline & Internet users $\mathrm{n}=308$ (81.1\%) & $\begin{array}{l}\text { Internet non-users, } \mathrm{n}=72 \\
(18.9 \%)\end{array}$ & Statistics \\
\hline \multicolumn{4}{|l|}{ Sex } \\
\hline Female & $125(40.6 \%)$ & $31(43.1 \%)$ & $X^{2}=0.147(d f=1)$ \\
\hline Male & $183(59.4 \%)$ & $41(56.9 \%)$ & $p=0.7$ \\
\hline Age, mean (SD) & $54.5(14.5)$ & $74.4(11.4)$ & $T=-11.016(d f=378), p<0.001$ \\
\hline \multicolumn{4}{|l|}{ Educational level } \\
\hline$<12$ years & $163(52.9 \%)$ & $67(93.1 \%)$ & $X^{2}=39.342(d f=1)$ \\
\hline$\geq 12$ years & $145(47.1 \%)$ & $5(6.9 \%)$ & $p<0.001$ \\
\hline \multicolumn{4}{|l|}{ Treatment } \\
\hline Dialysis patients, $1-5$ years & $62(20.1 \%)$ & $47(65.3 \%)$ & $X^{2}=91.758(d f=4), p<0.001$ \\
\hline Dialysis $>5$ years & $26(8.4 \%)$ & $14(19.4 \%)$ & \\
\hline Dialysis $>10$ years & $23(7.5 \%)$ & $9(12.5 \%)$ & \\
\hline Transplant patients & $165(53.6 \%)$ & $1(1.4 \%)$ & \\
\hline $\begin{array}{l}\text { CKD patients (no renal replacement } \\
\text { therapy) }\end{array}$ & $32(10.4 \%)$ & $1(1.4 \%)$ & \\
\hline
\end{tabular}

CKD chronic kidney disease

Table 3 Binary logistic regression analysis with user status as the dependent variable (users $=0$, non-users $=1$ )

\begin{tabular}{|c|c|c|c|c|c|c|c|c|}
\hline & $\begin{array}{l}\text { Regression } \\
\text { coefficient }\end{array}$ & Standard error & Wald & df & Sign & Odds ratio & 95\% CI Lower & 95\% Cl Upper \\
\hline $\operatorname{Sex}^{1}$ & -0.529 & 0.409 & 1.673 & 1 & 0.196 & 0.589 & 0.264 & 1.313 \\
\hline Age & 0.103 & 0.017 & 37.050 & 1 & $<0.001$ & 1.108 & 1.072 & 1.145 \\
\hline Treatment group ${ }^{2}$ & & & 19.271 & 4 & 0.001 & & & \\
\hline Dialysis $1-5$ yrs & 2.088 & 1.098 & 3.615 & 1 & 0.057 & 8.069 & 0.938 & 69.446 \\
\hline Dialysis > 5 yrs & 2.386 & 1.147 & 4.327 & 1 & 0.038 & 10.875 & 1.148 & 103.045 \\
\hline Dialysis > 10 yrs & 2.159 & 1.170 & 3.403 & 1 & 0.065 & 8.661 & 0.874 & 85.828 \\
\hline Transplantation & -1.882 & 1.470 & 1.640 & 1 & 0.200 & 0.152 & 0.009 & 2.713 \\
\hline Educational level $^{3}$ & 2.090 & 0.559 & 14.000 & 1 & $<0.001$ & 8.088 & 2.706 & 24.177 \\
\hline Konstante & -10.730 & 1.618 & 43.959 & 1 & $<0.001$ & 0.000 & & \\
\hline
\end{tabular}

Reference category: ${ }^{1}$ female, ${ }^{2}$ CKD group, ${ }^{3} \geq 12$ years of education 
patients (81.1\%) reported to use the internet on a daily basis (Table 2).

Within the group of internet users $26.6 \%$ stated they have used email to schedule visits and $11.7 \%$ have used e-mail to report symptoms. Only $2.6 \%$ have used video conferencing with their physician, $3.6 \%$ have used electronic medical records and $2.9 \%$ have used apps. These findings are displayed in Table 4 . In contrast $79.5 \%$ stated they would use email to schedule visits and $67.2 \%$ would use e-mail to report symptoms. $65.9 \%$ would use video conferencing with their physician, $73.4 \%$ would use electronic medical records and $75.6 \%$ would use apps. These findings are displayed in Table 5.

\section{Use of the internet to receive or submit medical information}

Within the group of internet users $68.2 \%$ stated that they are able to use the internet to receive information about health issues. Within the same group, $60.1 \%$ were convinced that they are able to distinguish between reliable and non-reliable sources. When asked if they used the internet to make decisions based on information on the internet $37.8 \%$ stated that they did. Concerns that personal medical data are not safe when submitted via the internet were stated by $35.4 \%$ of the internet users.

Table 4 Actual experiences of internet users $(n=308)$ with technologies of this kind within this specific context

\begin{tabular}{lc}
\hline & N (\%) \\
\hline Have used email to schedule visits & $82(26.6 \%)$ \\
Have used email to report symptoms & $36(11.7 \%)$ \\
Have used video conferencing with their physician & $8(2.6 \%)$ \\
Have used video conferencing with >1 physician at the & $4(1.3 \%)$ \\
same time & $11(3.6 \%)$ \\
Have used electronic medical records & $9(2.9 \%)$ \\
\hline
\end{tabular}

\section{Discussion}

Our study reveals that the majority of CKD patients in Germany $(81.1 \%)$ use the internet for general purposes, whereas $18.9 \%$ are nonusers. However, only a minority of users have experience with internet-based health care technologies. Different studies for the management and outcome of patients with chronic diseases, including patients with chronic kidney disease, imply that remote technologies may revolutionize the health care system regarding clinical outcome and cost reductions [27, 28]. In addition, mobile health apps are gaining popularity and more patients are supposed to use mobile technologies and informational websites to receive information about certain diseases and treatment opportunities [2931]. It is also anticipated that a variety of new internetbased approaches will flood the market in the near future especially with adolescents and younger adults as the target group [32]. However, despite the fact that in our study not many CKD patients were using internet-based health care technologies, the majority of patients are willing to consider the use within a medical context of consultation or treatment. In particular they are willing to use email to schedule visits or report symptoms, to do video conferencing with their physician and to use electronic medical records and apps. This is of clinical importance since it is well accepted that these technologies improve the medical outcome of this vulnerable patient group [19]. The use and expansion of internet technologies for CKD patients that address health care issues are politically supported and play an increasing role in health care systems worldwide. Especially since the declaration of the coronavirus disease 2019 (COVID-19) outbreak by the World Health Organization on March 11, 2020 as a pandemic, internet-based technologies, particularly video consultations, have been promoted and scaled up to reduce the risk of transmission almost worldwide [3, 33, 34]. Videoconferences seem to be practical, cost-effective and of interest for the vulnerable CKD patients in times of pandemics [33]. In spite of the fact that almost all CKD patients in our study have not used videoconferences so far, $62.3 \%$

Table 5 Willingness of adult internet users $(n=308)$ to consider the use of internet technologies within a medical context of consultation or treatment and their actual experiences with technologies of this kind within this specific context

\begin{tabular}{|c|c|c|c|}
\hline & Yes, would use, N (\%) & No, would not use, $\mathrm{N}(\%)$ & Missing, $n$ \\
\hline Would use email to schedule visits & $245(79.5 \%)$ & $48(15.6 \%)$ & $15(4.9 \%)$ \\
\hline Would use email to report symptoms & $207(67.2 \%)$ & $83(26.9 \%)$ & $18(5.8 \%)$ \\
\hline Would use video conferencing with their physician & $203(65.9 \%)$ & $89(28.9 \%)$ & $16(5.2 \%)$ \\
\hline Would use video conferencing with $>1$ physician at the same time & $192(62.3 \%)$ & $97(31.5 \%)$ & $19(6.2 \%)$ \\
\hline Would use electronic medical records & $226(73.4 \%)$ & $68(22.1 \%)$ & $14(4.5 \%)$ \\
\hline Would use apps & $233(75.6 \%)$ & $63(20.5 \%)$ & 12 (3.9\%) \\
\hline
\end{tabular}


are willing to consider their use for medical purposes. At his point it remains unclear why the patients are not using videoconferences with their physicians yet. Most likely videoconferences were not offered to the patients, the patients were not aware of the option or they just did not know how to set up video conferencing systems.

Only $2.9 \%$ of the participants in our study have used medical apps. Of interest, the majority, $75.6 \%$ of the applicants, report that they would consider using apps for health issues in the future. In contrast, a recent survey conducted by Paslakis et al. revealed that only $46.7 \%$ of the general adult population in Germany would use apps that offer personalized information about their condition and give recommendation for exercises and support [26]. We explain this discrepancy with the fact that the participants in our cohort suffer from a chronic disease and thus have had to deal with health topics already in the past, whereas healthy individuals in the general population may have not. In a study by Singh et al. it was revealed that CKD patients' impressions of quality of smart-phone apps were not directly linked to nephrologist ratings [35]. Guidelines and quality checks of internet related health resources may be therefore of significant relevance to ensure high standards for the consumers.

More internet users with CKD would consider the use of internet technologies to communicate with their physicians compared to the general German population [26]. Again, this may be due to the fact that CKD patients have frequent contact with their physician and are probably more aware of the benefits.

Well in line with other studies, the digital divide was also apparent in our study where, not surprisingly, nonusers were significantly older and had a lower educational level than the group of internet users. This is especially problematic, since statistically these patients suffer the most from a variety of different chronic diseases and would benefit the most from internet based technologies and health support [36]. In our study nonusers were more likely to be on dialysis as opposed to being transplanted. However, being on dialysis cannot be seen as an independent variable for being a nonuser, since our dialysis patients were significantly older (Table 6). This is well in line with the findings of Taylor et al. who described previously that patients with higher educational level and health literacy were more often selected for kidney transplantation [37].

As mentioned above, a variety of studies suggest that there are benefits of internet-based technologies for health care issues. In this context, it has to be considered that in studies that analyze the benefits of eHealth systems for patient management, the participants were usually recruited from an already interested group of
Table 6 Median age per treatment group

\begin{tabular}{ll}
\hline Treatment & Age, years (SD) \\
\hline Treatment & \\
Dialysis patients, 1-5 yrs & $65.8(16.3)$ \\
Dialysis > 5 years & $62.2(14.1)$ \\
Dialysis > 10 years & $58.9(13.5)$ \\
Transplant patients & $52.9(14.7)$ \\
CKD patients & $53.2(15.1)$ \\
\hline
\end{tabular}

The median age of the participants was 58 years

patients. Ong et al. therefore postulate that these studies may be prone to selection bias since patients without an affinity to internet-based technologies were presumably not included as participants [21]. Our study also has several limitations. In our set-up, it was possible for the participants to submit the questionnaire either via the internet or by using a prepaid regular mail envelope and both submission methods were used almost equally. However, it is possible that there are actually more nonusers since non-users only had the mail-in option to submit the survey. Secondly, it is a national survey study with a limited number of participants who might not be representative of the German CKD population or CKD populations in other countries. Moreover, selection bias due to the distribution of the questionnaire and the exclusion of participants with incomplete questionnaire data is possible. Furthermore, we did not use a validated questionnaire but a series of questions generated by experts in nephrology who were also involved in the questionnaire design in the study by Paslakis et al., to make the results comparable to the findings in the general German population.

\section{Conclusions}

The majority of internet-users in our survey reported that they would consider internet-based technologies within a medical context of consultation or treatment. The percentage of CKD patients willing to use internetbased health care delivery is higher than in the general German population. However, we found that almost $20 \%$ of CKD patients, especially older patients and patients with a lower educational level, did not use the internet at all. Therefore, it seems to be of great relevance to identify motivated CKD patients in order to introduce high-quality internet-based health care technologies to them. In addition, there should be a focus on outreach to elderly CKD patients and patients with a lower educational level. This concept could also provide a helpful blueprint for health systems in other countries. We believe that for the 
successful implementation of internet-based health care delivery for patients with chronic kidney disease, fully funded "teaching points" should be established and the effects should be assessed by clinical studies.

\section{Supplementary Information}

The online version contains supplementary material available at https://doi. org/10.1186/s12911-020-01375-9.

Additional file 1: Supplementary information about the questionaire.

Additional file 2: Figure S1. Participant distribution in Germany based on postal code. Postal code analysis of patients revealed that patients from all over Germany participated in the survey. The majority of patients that participated were recruited in postal area 3 and 9 where the innovation fonds study ktx $360^{\circ}$ is actively running at Hannover Medical School, kidney transplant center Hann. Münden and University Hospital Erlangen (postal code area map modified from www.venue.de)

\section{Abbreviation}

CKD: Chronic kidney disease.

\section{Acknowledgements}

We thank Prof. Wanja Bernhardt and Dr. Christine Koch for support in distribution of the survey.

\section{Authors' contributions}

$L S, L P, M d Z$ and $M S$ designed and conducted the study, processed statistical data and drafted the manuscript. RG, MN, ES and UT enabled and supported the realization of the study. All authors revised the manuscript critically for intellectual content and gave full approval of the version to be published and agree to be accountable for all aspects of the work. All authors read and approved the final version of the manuscript.

\section{Funding}

NT $\times 360^{\circ}$ is supported by a grant from the Federal Joint Committee of the Federal Republic of Germany (Number 01NVF16009). The survey was a substudy of NT $\times 360^{\circ}$. The funding agency was not involved in the design of the study, data collection, data analysis and data interpretation.

\section{Availability of data and materials}

Not applicable.

\section{Ethics approval and consent to participate}

The study was approved by the ethics committee of the Medical School of Hannover. Consent was obtained from all participants, online, before the questionnaire itself could be attempted. The manuscript does not contain individual person's data.

\section{Consent for publication}

The consent to participate included consent for publication of results.

\section{Competing interests}

The authors declare that they have no competing interests..

\section{Author details}

${ }^{1}$ Department of Pediatric Kidney, Liver and Metabolic Diseases, Hannover Medical School, Carl Neuberg Str. 1, 30625 Hannover, Germany. ${ }^{2}$ Department of Psychosomatic Medicine and Psychotherapy, Hannover Medical School, Hannover, Germany. ${ }^{3}$ Department of Nephrology, University Hospital, Friedrich-Alexander University, Erlangen, Germany. ${ }^{4}$ Project Kidney Transplantation $360^{\circ}$, Hannover Medical School, Hannover, Germany. ${ }^{5}$ Department of Sports Medicine, Hannover Medical School, Hannover, Germany.

Received: 26 April 2020 Accepted: 17 December 2020

Published online: 01 February 2021

\section{References}

1. Eysenbach G, Powell J, Kuss O, Sa ER. Empirical studies assessing the quality of health information for consumers on the world wide web: a systematic review. JAMA. 2002;287(20):2691-700.

2. Wynn R. E-Health in Norway before and during the initial phase of the Covid-19 pandemic. Stud Health Technol Inform. 2020;272:9-12.

3. Hollander JE, Carr BG. Virtually perfect? Telemedicine for Covid-19. N Engl J Med. 2020;382(18):1679-81.

4. Verma S. Early impact of CMS expansion of medicare telehealth during COVID-19. Health Affairs Blog. 2020.

5. Elbert NJ, van Os-Medendorp H, van Renselaar W, Ekeland AG, Hakkaartvan Roijen L, Raat $H$, et al. Effectiveness and cost-effectiveness of ehealth interventions in somatic diseases: a systematic review of systematic reviews and meta-analyses. J Med Internet Res. 2014;16(4):e110.

6. Rushakoff RJ, Rushakoff JA, Kornberg Z, MacMaster HW, Shah AD. Remote monitoring and consultation of inpatient populations with diabetes. Curr Diab Rep. 2017;17(9):70.

7. Al-Durra M, Torio MB, Cafazzo JA. The use of behavior change theory in Internet-based asthma self-management interventions: a systematic review. J Med Internet Res. 2015;17(4):e89.

8. van der Eijk M, Faber MJ, Aarts JW, Kremer JA, Munneke M, Bloem BR. Using online health communities to deliver patient-centered care to people with chronic conditions. J Med Internet Res. 2013;15(6):e115.

9. Bieber SD, Weiner DE. Telehealth and home dialysis: a new option for patients in the United States. Clin J Am Soc Nephrol. 2018;13(8):1288-90.

10. Gregor-Haack J. Reimbursement of health apps by the German statutory health insurance. Bundesgesundheitsblatt. 2018;61 (3):328-33.

11. Albrecht UV, Kuhn B, Land J, Amelung VE, von Jan U. Assessing the benefits of digital health solutions in the societal reimbursement context. Bundesgesundheitsblatt. 2018;61(3):340-8.

12. Leppert F, Gerlach J, Ostwald DA, Greiner W. Strength and weaknesses of the German digital health economy. Gesundheitswesen. 2018;80(11):946-52.

13. Pape L, de Zwaan M, Tegtbur U, Feldhaus F, Wolff JK, Schiffer L, et al. The KT×360 degrees-study: a multicenter, multisectoral, multimodal, telemedicine-based follow-up care model to improve care and reduce health-care costs after kidney transplantation in children and adults. BMC Health Serv Res. 2017:17(1):587.

14. Pape L, Schneider N, Schleef T, Junius-Walker U, Haller H, Brunkhorst $\mathrm{R}$, et al. The nephrology eHealth-system of the metropolitan region of Hannover for digitalization of care, establishment of decision support systems and analysis of health care quality. BMC Med Inform Decis Mak. 2019;19(1):176.

15. Hill NR, Fatoba ST, Oke JL, Hirst JA, O'Callaghan CA, Lasserson DS, et al. Global prevalence of chronic kidney disease-a systematic review and meta-analysis. PLoS ONE. 2016;11(7):e0158765.

16. Zhang QL, Rothenbacher D. Prevalence of chronic kidney disease in population-based studies: systematic review. BMC Public Health. 2008;8:117.

17. Glassock RJ, Warnock DG, Delanaye P. The global burden of chronic kidney disease: estimates, variability and pitfalls. Nat Rev Nephrol. 2017;13(2):104-14.

18. Albertus P, Morgenstern H, Robinson B, Saran R. Risk of ESRD in the United States. Am J Kidney Dis. 2016;68(6):862-72.

19. Stevenson JK, Campbell ZC, Webster AC, Chow CK, Tong A, Craig JC, et al. eHealth interventions for people with chronic kidney disease. Cochrane Database Syst Rev. 2019;8:Cd012379.

20. Thilly N, Chanliau J, Frimat L, Combe C, Merville P, Chauveau P, et al. Costeffectiveness of home telemonitoring in chronic kidney disease patients at different stages by a pragmatic randomized controlled trial (eNephro): rationale and study design. BMC Nephrol. 2017;18(1):126

21. Ong SW, Jassal SV, Miller JA, Porter EC, Cafazzo JA, Seto E, et al. Integrating a smartphone-based self-management system into usual care of advanced CKD. Clin J Am Soc Nephrol. 2016;1 1(6):1054-62.

22. Kaier K, Hils S, Fetzer S, Hehn P, Schmid A, Hauschke D, et al. Results of a randomized controlled trial analyzing telemedically supported case management in the first year after living donor kidney transplantationa budget impact analysis from the healthcare perspective. Health Econ Rev. 2017:7(1):1

23. Rosner MH, Lew SQ, Conway P, Ehrlich J, Jarrin R, Patel UD, et al. Perspectives from the kidney health initiative on advancing technologies to 
facilitate remote monitoring of patient self-care in RRT. Clin J Am Soc Nephrol. 2017;12(11):1900-9.

24. McCullough KP, Morgenstern H, Saran R, Herman WH, Robinson BM Projecting ESRD incidence and prevalence in the United States through 2030. J Am Soc Nephrol. 2019;30(1):127-35.

25. Heponiemi T, Jormanainen V, Leemann L, Manderbacka K, Aalto AM, Hypponen H. Digital divide in perceived benefits of online health care and social welfare services: national cross-sectional survey study. J Med Internet Res. 2020;22(7):e17616.

26. Paslakis G, Fischer-Jacobs J, Pape L, Schiffer M, Gertges R, Tegtbur U, et al. Assessment of use and preferences regarding internet-based health care delivery: cross-sectional questionnaire study. J Med Internet Res. 2019;21(5):e12416.

27. Tan J, Mehrotra A, Nadkarni GN, He JC, Langhoff E, Post J, et al. Telenephrology: providing healthcare to remotely located patients with chronic kidney disease. Am J Nephrol. 2018:47(3):200-7.

28. He T, Liu X, LiY, Wu Q, Liu M, Yuan H. Remote home management for chronic kidney disease: a systematic review. J Telemed Telecare. 2017;23(1):3-13.

29. Siddique AB, Krebs M, Alvarez S, Greenspan I, Patel A, Kinsolving J, et al. Mobile apps for the care management of chronic kidney and end-stage renal diseases: systematic search in app stores and evaluation. JMIR Mhealth Uhealth. 2019;7(9):e12604.

30. Doyle N, Murphy M, Brennan L, Waugh A, McCann M, Mellotte G. The "Mikidney" smartphone app pilot study: empowering patients with chronic kidney disease. J Ren Care. 2019;45(3):133-40.
31. Scott IA, Scuffham P, Gupta D, Harch TM, Borchi J, Richards B. Going digital: a narrative overview of the effects, quality and utility of mobile apps in chronic disease self-management. Aust Health Rev. 2018.

32. Low JK, Manias E. Use of technology-based tools to support adolescents and young adults with chronic disease: systematic review and metaanalysis. JMIR Mhealth Uhealth. 2019;7(7):e12042.

33. Greenhalgh T, Wherton J, Shaw S, Morrison C. Video consultations for Covid-19. BMJ. 2020;368:m998.

34. Dorsey ER, Topol EJ. Telemedicine 2020 and the next decade. Lancet. 2020;395(10227):859.

35. Singh K, Diamantidis CJ, Ramani S, Bhavsar NA, Mara P, Warner J, et al. Patients' and nephrologists' evaluation of patient-facing smartphone apps for CKD. Clin J Am Soc Nephrol. 2019;14(4):523-9.

36. Lowry R, Kann L, Collins JL, Kolbe $L$. The effect of socioeconomic status on chronic disease risk behaviors among US adolescents. JAMA. 1996;276(10):792-7.

37. Taylor DM, Bradley JA, Bradley C, Draper H, Dudley C, Fogarty D, et al. Limited health literacy is associated with reduced access to kidney transplantation. Kidney Int. 2019;95(5):1244-52.

\section{Publisher's Note}

Springer Nature remains neutral with regard to jurisdictional claims in published maps and institutional affiliations.
Ready to submit your research? Choose BMC and benefit from:

- fast, convenient online submission

- thorough peer review by experienced researchers in your field

- rapid publication on acceptance

- support for research data, including large and complex data types

- gold Open Access which fosters wider collaboration and increased citations

- maximum visibility for your research: over 100M website views per year

At BMC, research is always in progress.

Learn more biomedcentral.com/submissions 